\section{Dusty satellite}

Icarus doi:10.1016/j.icarus.2011.06.027 (2011)

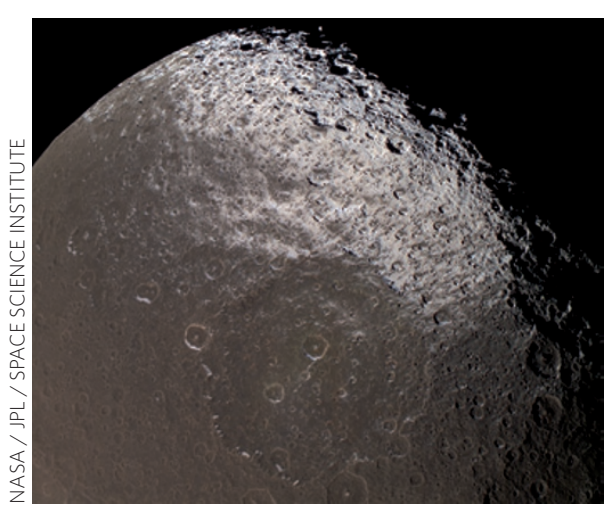

The trailing side of Saturn's moon Iapetus is far more reflective than its leading face. Modelling of dust collision paths suggests that the dark side is less reflective because of a covering of dust that originates from another of Saturn's moons, Phoebe.

Saturn's satellites have experienced intense, dust-generating collisions between each other and from meteoroid impacts. Daniel Tamayo at Cornell University and colleagues calculated the probability that dust from three dozen satellites of Saturn, including Phoebe, will strike the originally bright Iapetus. They found that large dust particles are almost certain to hit Iapetus. The calculated distribution of the dust particles on the surface of Iapetus matches the dark area observed in the images taken by the Cassini mission.

The researchers also show that a tiny amount of the dust from Phoebe will hit another of Saturn's moons - Hyperion. Because Hyperion has a chaotic rotation, the dust is distributed quite uniformly across the moon's surface, causing the moon to be only moderately reflective.

$A W$

\section{Fire and climate \\ Geophys. Res. Lett. \\ doi:10.1029/2011GL047674 (2011)}

Reconstructions suggest that a key determinant of wildfire activity in South America is the Southern Annular Mode - the dominant mode of climate variability in the mid-to-high latitude Southern Hemisphere.

Andrés Holz and Thomas Veblen of the University of Colorado, Boulder, used treering data to reconstruct wildfire activity in dry woodlands in northern Patagonia and temperate rainforests in southern Chile over the past two and a half centuries. They show that years of widespread fire activity are associated with the positive phase of the Southern Annular Mode, which is characterized by higher temperatures and reduced rainfall in the region. Conversely, firefree years coincide with the negative, wetter phase of the Southern Annular Mode.

Positive phases of the Southern Annular Mode are projected to increase in frequency this century. The researchers suggest this will enhance wildfire activity in the southern half of South America.

\section{African mineral makers} Biogeosciences 8, 1755-1767 (2011)

Carbonate accumulates in soils surrounding the African iroko tree, owing to the conversion of the plant metabolite oxalate into carbonate minerals. A field study suggests that carbonate formation takes place in the soil, following the decomposition of tree debris.

Guillaume Cailleau of the University of Lausanne, Switzerland, and colleagues assessed the distribution of oxalate and carbonate minerals in iroko forests in Cameroon and the
Ivory Coast. They found high concentrations of oxalate crystals in the bark and wood of the iroko trees. A build up of these crystals in the soils surrounding recently felled trees suggests that the oxalate crystals are released into the soil following decomposition of the tree matter. On release, soil bacteria convert the crystals into carbonate minerals.

Given that oxalate accumulation is common in many groups of tropical plants, the researchers suggest that carbonate formation could be an important process in tropical soilcarbon dynamics; the build up of carbonate may result in the sequestration of carbon.

\section{Sea-ice maximum}

Quat. Sci.Rev.

doi:10.1016/j.quascirev.2011.04.002 (2011)



At the end of the last glacial period, the summertime extent of sea ice in the Southern Ocean began to decline thousands of years before winter cover, according to an analysis of marine sediment records.

Claire Allen of the British Antarctic Survey and co-workers searched marine sediment cores from the Scotia Sea for the fossil remains of diatoms that live in or near sea ice. They found that sea ice reached its most northerly latitude at $52^{\circ} \mathrm{S}$ during the winter and $59^{\circ} \mathrm{S}$ during the summer sometime after 30,000 years ago. However, the summer limits of ice retreated to $61^{\circ} \mathrm{S}$ by 22,000 years ago, whereas winter sea ice remained at its maximum extent until 19,000 years ago. The team suggests the summer retreat was caused by changes in summer or springtime incoming solar radiation

The brines formed by the refreezing of winter sea ice over such a large area could have increased the density of the water sinking to form bottom water, which in turn would promote the northward expansion of Antarctic Bottom Water.

Written by Amy Whitchurch, Anna Armstrong and Alicia Newton. 